\title{
Shoulder Dislocation with Head and Shaft Fracture Ipsilateral
}

Tomás Pérez Cervera*, Luis Roca and Miguel Ángel Martín Montalvo

Hospital Universitario Virgen Macarena Sevilla, Spain

\begin{abstract}
Accompanied shoulder dislocation of the proximal humerus fracture associated with ipsilateral shaft fracture is a rare injury described in literature collection and whose treatment protocol is not clearly established.

Here we present the case of 63 years old male who suffered a fall after slipping in a pool and presented a humeral shaft fracture associated with ipsilateral anterior glenohumeral dislocation and fracture of the proximal humerus in three fragments with involvement of the anatomical neck. The patient underwent a closed reduction first attempt with the help of two needle percutaneous. Axillary artery was injured so had to undergo a second time for another intervention in which we made open reduction and osteosynthesis by proximal humerus long plate and hemiarthroplasty.
\end{abstract}

Keywords: Shoulder dislocation with shaft fracture; Humeral shaft fractures with dislocation; Proximal humerus fracture and shaft fracture

\section{Introduction}

Anterior glenohumeral dislocation associated with ipsilateral shaft fracture is a rare injury. The first case in modern literature was described in 1940 by Winderman. Since then, 24 new cases have been described by others (Table 1) [1].

These injuries often occur as a result of high energy trauma. The literature concerning this rare lesion is limited to "case reports", within which there are different treatments applied [2].

The purpose why we report this case it is to show the different options of treatment for an unusual injury which was treated with hemiarthroplasty with plate screws fixation of shaft.

\section{Case History}

The patient was a 63 year old male slipped in a pool and fell on his right arm. On arrival to the emergency room right arm and shoulder were sore, swollen and deformed.

Clinical examination showed right shoulder deformity to the middle third diaphyseal with no neurovascular abnormalities. Also anterior displacement of the head and a positive sulcus sign was found.

Radiographs showed a spiral fracture of the humeral shaft with lateral angulation, three parts anatomic neck fracture and anterior glenohumeral dislocation (Figures 1 and 2).

Firstly, in the operating room, under general anesthesia closed reduction of anterior dislocation using two percutaneous pinning was attempted but it was impossible to reduce it [3]. When we removed the needles, bleeding is observed by one of the inlets of the needles which refers to maintaining compression.

Weak radial pulse was palpable without uptake in the $\mathrm{O}_{2}$ sensor so vascular injury was suspected and Hemodynamic Vascular Surgeon was informed.

Vascular surgeons confirmed a small tear at the level of the axillary artery which was sutured. This complication forced us to delay the final intervention for about five days.

Secondly, under new general anesthesia, new closed reduction was attempted without success.
Thus, using extended deltopectoral approach we were able to obtain the reduction of the humeral head, though not without difficulties.

Once the fracture is reduced, we noted the existence of a proximal humerus fracture in 3 fragments with involvement of the anatomical neck and spiral fracture of the shaft.

Due to increased risk of necrosis of the humeral head, we consider the optimal treatment was the placement of a cemented humeral

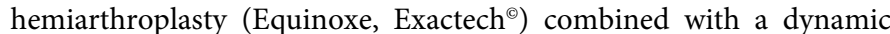
long compression plate for proximal humerus (Periloc. Smith and Nephew@) and three cerclages Dall-Miles (Figures 3 and 4).

Layered closure was performed with a suction drain wich was removed in 24 hours. The radiological result is shown in Figures 5 and 6.

\section{Discussion}

In the current literature there is not any case of humeral shaft fracture combined with fracture - dislocation of the humeral head affecting the ipsilateral and anatomical neck. Since 1940 only 24 cases of fractures-dislocations of the humeral head with ipsilateral shaft fractures have been described (Table 1) [1]. Five of them described greater tuberosity fracture. One article described a proximal humerus fracture in three fragments, but without involvement of the anatomical neck, hence the uniqueness of our case. The majority of reported cases has occurred as a result of high energy trauma, unlike ours that was for a simple accidental fall after slipping on a wet floor $[4,5]$.

In previous publications, the injuries were caused by traffic accidents involving motorcycles or cars, precipitation from two or more meters high or even workplace machinery accidents.

*Corresponding author: Tomás Pérez Cervera, Hospital Universitario Virgen Macarena, Ciurgía Ortopédica y Traumatología, Sevilla 41018, Spain, Tel: +34660276344; E-mail: tperezc86@gmail.com

Received January 07, 2016; Accepted February 25, 2016; Published March 03 , 2016

Citation: Cervera TP, Roca L, Montalvo MÁM (2016) Shoulder Dislocation with Head and Shaft Fracture Ipsilateral. J Arthritis 5: 194. doi:10.4172/21677921.1000194

Copyright: @ 2016 Cervera TP, et al. This is an open-access article distributed under the terms of the Creative Commons Attribution License, which permits unrestricted use, distribution, and reproduction in any medium, provided the original author and source are credited. 
Citation: Cervera TP, Roca L, Montalvo MÁM (2016) Shoulder Dislocation with Head and Shaft Fracture Ipsilateral. J Arthritis 5: 194. doi:10.4172/21677921.1000194

Page 2 of 4

\begin{tabular}{|c|c|c|c|c|c|c|c|}
\hline Author/Dot & dapOsna & & Ditdorodon & $\begin{array}{c}\text { MIMI } \\
\text { linarmeo }\end{array}$ & 114slotadaa Th & Press TY & Anlb \\
\hline & & \multicolumn{2}{|c|}{ Madbanias } & & & & \\
\hline IImit.3)04 & Me F & Pal & Animate 3 gun & $\mathrm{Md} . / 3$ & Owed & Ceoptanim SSW & Good \\
\hline Inattrainel & $: 111$ & conerrer belt & Anterior. CIF & $\mathrm{M} 4 / 3$ & Closed & ()RIF Dynamic Coadermoon Fit & Good \\
\hline howthlare206 & $\ln 31$ & MCC & Amain & htsa/3 & Chord & Reddns \& lawnersedullan Nat & (Mod \\
\hline \multirow[t]{3}{*}{4 Ism/ litnl } & IS M & MCC & Armand & Miblesill & (bird & Dynamic & Good \\
\hline & & & & & & \multicolumn{2}{|c|}{ Corapremion Fide and Scream } \\
\hline & :OM & MCC & Antrnar & Ian Ituttertb & timed & IMF Dynamic Conan-dim nor & Rota $\mathrm{n}$ rakey \\
\hline \multirow[t]{2}{*}{ Mafia/1996 } & $19 \mathrm{M}$ & MST & Ant, ...( t. i: & $\begin{array}{l}\text { Maiand/ } 3 \\
\text { Itrandly }\end{array}$ & timed & Druids & Inv Abl \\
\hline & & & & & & Compredost lido & DI 13drg, Ore nrsi IR 10 \\
\hline \multirow[t]{2}{*}{ Caladoor/1106 } & 7711 & MW & Ammar & Slid/3 & aimed & Dynamic Comanweion liar & Ibatial n Paley. \\
\hline & & & & & & & riwohrd \\
\hline \multirow[t]{2}{*}{ Daekt/ 1995} & $29 U$ & MCC & Animist & Ibath/3 & Closed & Stsba/Brace & CS7 *sopa. nesolord \\
\hline & 6711 & WIC & Minim & $\mathrm{M} / 3$ & Owed & latnamord. Rod & lambed aid. litic wad IX \\
\hline \multirow[t]{3}{*}{ KontakiV10111 } & II 14 & /417C & Anterior & $114 / 3$ & Opts & & Mr Si. aid. and ER 10 \\
\hline & & & & & & Hale and Screwy & dee \\
\hline & 4131 & Fa tom 201 & Antedate & 16113 & Clad & 1T-Slab (SAN) & the FR to dew \\
\hline Commilld4 & 1611 & MCC & Anardoe & Mid./3 & Chord & $\begin{array}{c}3 \text { tin stahaanbai } . r 1 \text { la Lethal } \\
\text { bxImlemw }\end{array}$ & (Dyed \\
\hline Stephens. Kotty/lleol & 2931 & MW & Amnion GTV & $\mathrm{M} 4 / 3$ & $\begin{array}{c}\text { Closed it/ limb } \\
\text { Lenge:dab* } \\
\text { APPrlttwt to Amid }\end{array}$ & $\begin{array}{c}\text { Clewed Itedurnew Edema 11A } \\
\text { Elation }\end{array}$ & Ibw Abd M dna \\
\hline \multirow[t]{3}{*}{$\mathrm{lb}: 1 \mathrm{pm} /$ ttes 3} & 2.511 & $\begin{array}{l}\text { Operating } \\
\text { Maidnery } 0 \\
\text { Tracduad }\end{array}$ & Animist. GIP & $\begin{array}{l}\text { Mal Loy/ } 3 \\
\text { hand }^{*}\end{array}$ & Gamed & 501111 & Good \\
\hline & $\mathrm{CV}$ & MW & Antsdne & $\operatorname{limn}$ & $\begin{array}{l}\text { nomad w/ } \\
\text { Sielawada }\end{array}$ & SWIM & Good \\
\hline & & & & & pin & & \\
\hline \multirow[t]{2}{*}{ Bake/1971 } & $25 !$ & $\begin{array}{l}\text { Oweratint Mad/ } \\
\text { marry }\end{array}$ & Antral $^{*}$. G17 & $\mathrm{Mid} / 3$ & ORO & latranedsdbry Raab & $74 \mathrm{~km} . \mathrm{MA}$ malmetat \\
\hline & & efalb & & & & OW & \\
\hline Gu1/19S7• & $\mathrm{n} / \mathrm{a}$ & $\mathrm{n} / \mathrm{a}$ & $\&$ ardor & Finsil & $\mathrm{n} / \mathrm{a}$ & $\mathrm{a} / \mathrm{a}$ & $a / a$ \\
\hline 110bn/1911 & $a / a$ & $\mathrm{n} / \mathrm{a}$ & $\mathrm{n} / \mathrm{a}$ & $\mathrm{n} / \mathrm{a}$ & st/o & $\mathrm{n} / \mathrm{a}$ & $a / a$ \\
\hline \multirow[t]{2}{*}{ Windermid/ HMO } & $614 \mathrm{~F}$ & bll & Submwaroid & $\mathrm{Mi} 1 / 3$ & Owed math On & Split & $\begin{array}{c}\text { Gaol M0690. Dimbred } \\
\text { a karate }\end{array}$ \\
\hline & & & & & Oo avid & & \\
\hline Mth/1919 & '1711 & Fall dome stars & Submaratold & Proa/3 & Closed & SPIN & $\begin{array}{c}\text { roll 11011. time rwrw- } \\
\text { Dt^Llfo;fl'U!a }\end{array}$ \\
\hline
\end{tabular}

-ubuietd atom Ranson $111 \mathrm{~K} 1 /$

Table 1: This table mimes the trimeted powlsosd bumf we Inctursw1okrations Mai awcanded hewn trastsrms Owls trmaarat aid antra.

We must emphasize the mechanism of injury. Case reports in the literature have advocated two possible mechanisms of injury. SankaranKutty and Sadat-Ali [6] suggested that the force exerted along the axis of the humerus simultaneously fractured the humerus and dislocated the shoulder, whereas Kontakis et al. $[7,8]$ proposed that the shoulder dislocated first and subsequent, bending or torsion forces fractured the shaft of humerus. We believe that the mechanism of injury in our patient was as described in the second case, and this is supported by the fracture pattern that is spiral and acute bending of the arm during emergency presentation.

In a prospective study developed by Court - Brown showed that $49 \%$ of proximal humerus fractures were classified as Neer Type I. $28 \%$ was classified as broken into two fragments of the surgical neck and only $9 \%$ as fractures into three fragments with greater tuberosity and fitness for repair broken neck. Our patient was classified as a fracture in three fragments with the peculiarity of the anatomical neck fracture.
The humeral head receives vascular supply through the anterior circumflex artery and to a lesser extent is also nourished by vessels entering through the posteromedial region of the proximal humerus, and metaphyseal vessels of the tuberosity. Doppler confirmed that if the humeral head fragments include at least $8 \mathrm{~mm}$ medial calcar, avascular necrosis risk drops significantly due to the blood pool present there. It also determined that avascular necrosis was ahead in $97 \%$ of cases if they had an anatomical neck fracture, small medial calcar and periosteal disruption of the medial line.

Our patient had a fracture of the anatomical neck, so he had a high risk of avascular necrosis to which must be added the time elapsed since the injury until surgery.

Fractures in three fragments of the proximal humerus with dislocations associated with ipsilateral humeral shaft fractures are rare. The closed each of these lesions is suitably reduced, if it is possible 
Citation: Cervera TP, Roca L, Montalvo MÁM (2016) Shoulder Dislocation with Head and Shaft Fracture Ipsilateral. J Arthritis 5: 194. doi:10.4172/2167-

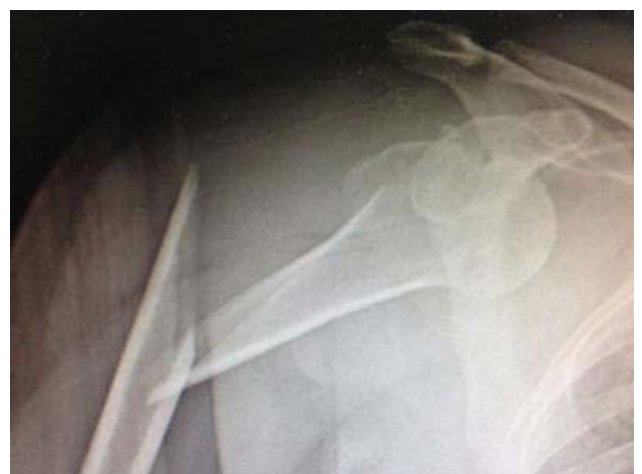

Figure 1: Rx shows fracture - dislocation with ipsilateral shaft fracture

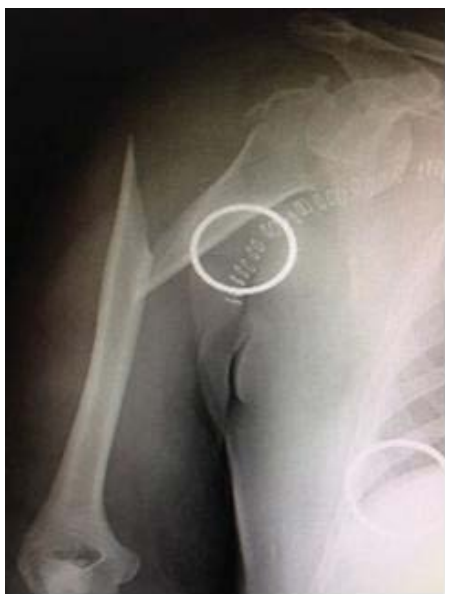

Figure 2: Rx shows fracture in three parts with anatomical neck fracture.

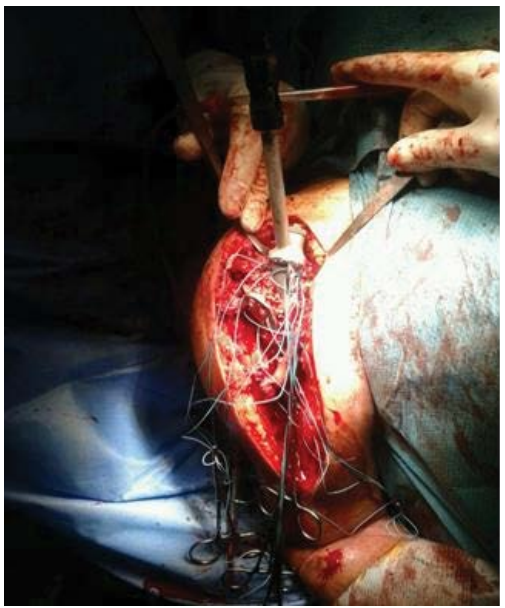

Figure 3: DLCP and hemiarthroplasty during their collocation.

to do in emergencies, which will preserve blood flow to the fracture fragments.

The second important aspect of our case is its management. Literature reflects that hemiartroplasty may be a viable option for complex fractures of the proximal humerus with even better results than open reduction and fixation [9]. The treatment modalities include closed reduction and plaster of paris slab application, nailing and plating of the humeral shaft along with reduction of the shoulder dislocation. Good clinical results have been reported with almost all the modalities. However, there is no consensus in the literature for treating this type of injury [10-12]. In fact, we did a combination of several options to

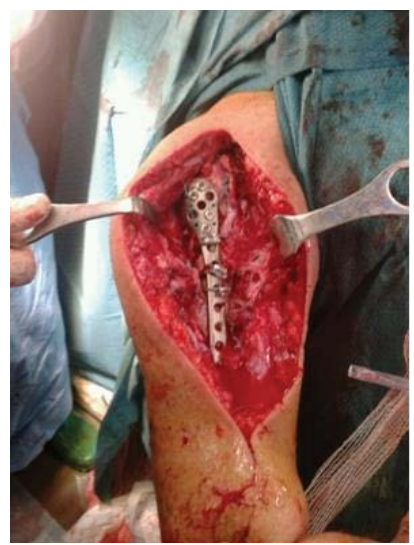

Figure 4: DLCP with hemiarthroplasty and cerclages.

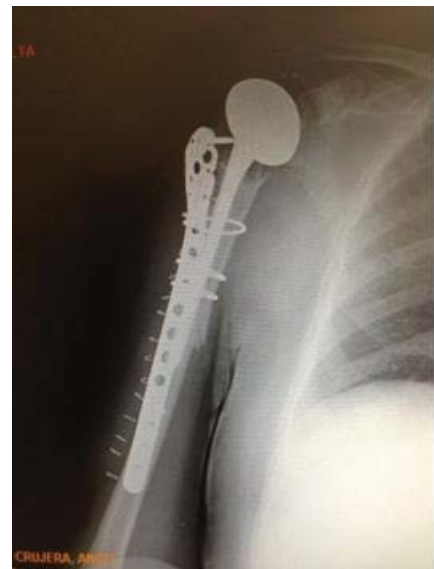

Figure 5: Postsurgery Rx

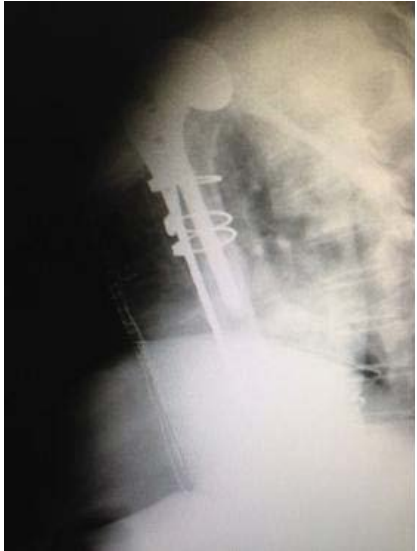

Figure 6: Radiological result. 
Citation: Cervera TP, Roca L, Montalvo MÁM (2016) Shoulder Dislocation with Head and Shaft Fracture Ipsilateral. J Arthritis 5: 194. doi:10.4172/21677921.1000194

overcome the difficulties we were facing for the internal fixation of the fracture and for the viability of the humeral head.

The last aspect of this case is its outcome. Almost all reported cases have reported satisfactory outcome (some degree of restriction of abduction and flexion) despite different modalities of management. We also had a good outcome in our patient despite having a more severe injury.

\section{References}

1. Karimi-Nasab MH, Shayesteh-Azar M, Sajjadi-Saravi M, Daneshpoor SMM (2012) Anterior shoulder dislocation and ipsilateral humeral shaft fracture. Iran J Med Sci 37: 202-204.

2. Kazakos K, Paraschou S, Lasanianos N, Verettas D, Lyras D (2009) A humeral shaft fracture complicated with anterior shoulder dislocation in a young male treated with modified Intramedullary nailing prior to reduction: a case report. Cases Journal 2: 9075

3. Flint JH, Carlyle LM, Christiansen CC, Nepola JV (2009) Case report and literature review anterior shoulder dislocation with three-part proximal humerus fracture and humeral shaft fracture. lowa Orthop J 29: 105-113.

4. Inan U, Cevik AA, Omeroğlu H (2008) Open humerus shaft fracture with ipsilateral anterior shoulder fracture-dislocation and posterior elbow dislocation: a case report. J Trauma 64: 1383-1386.
5. Calderone RR, Ghobadi F, Mclnerney V (1995) Treatment of shoulder dislocation with ipsilateral humeral shaft fracture. Am J Orthop (Belle Mead NJ) 24: 173-176.

6. Sankaran-Kutty M, Sadat-Ali M (1989) Dislocation of the shoulder with ipsilateral humeral shaft fracture. Arch Orthop Trauma Surg 108: 60-62.

7. Kontakis GM, Galanakis IA, Steriopoulos KA (1995) Dislocation of the shoulder and ipsilateral fracture of the humeral shaft: case reports and literature review. J Trauma 39: 990-992.

8. Gupta Y, Jha RK (2015) Compound fracture of humeral shaft associated with two-part fracture dislocation of ipsilateral shoulder: a rare combination. J Surg Case Rep 2015.

9. Sasashige Y, Kurata T, Masuda Y, Shimono K, Nagata Y (2006) Dislocation of the shoulder joint with ipsilateral humeral shaft fracture: two case reports. Arch Orthop Trauma Surg 126: 562-567.

10. Behera P, Kumar V, Aggarwal S (2014) Humeral shaft fracture with ipsilateral shoulder dislocation. Chin J Traumatol 17: 57-59.

11. Micic ID, Mitkovic MB, Mladenovic DS (2005) Unreduced chronic dislocation of the humeral head with ipsilateral humeral shaft fracture: a case report. J Orthop Trauma 19: 578-581.

12. Farooque K, Khatri K, Dev C, Sharma V, Gupta B (2014) Mechanism of injury and management in traumatic anterior shoulder dislocation with concomitant humeral shaft and ipsilateral scapula fracture: a case report and review of the literature. Journal of Medical Case Reports 8: 431. 